
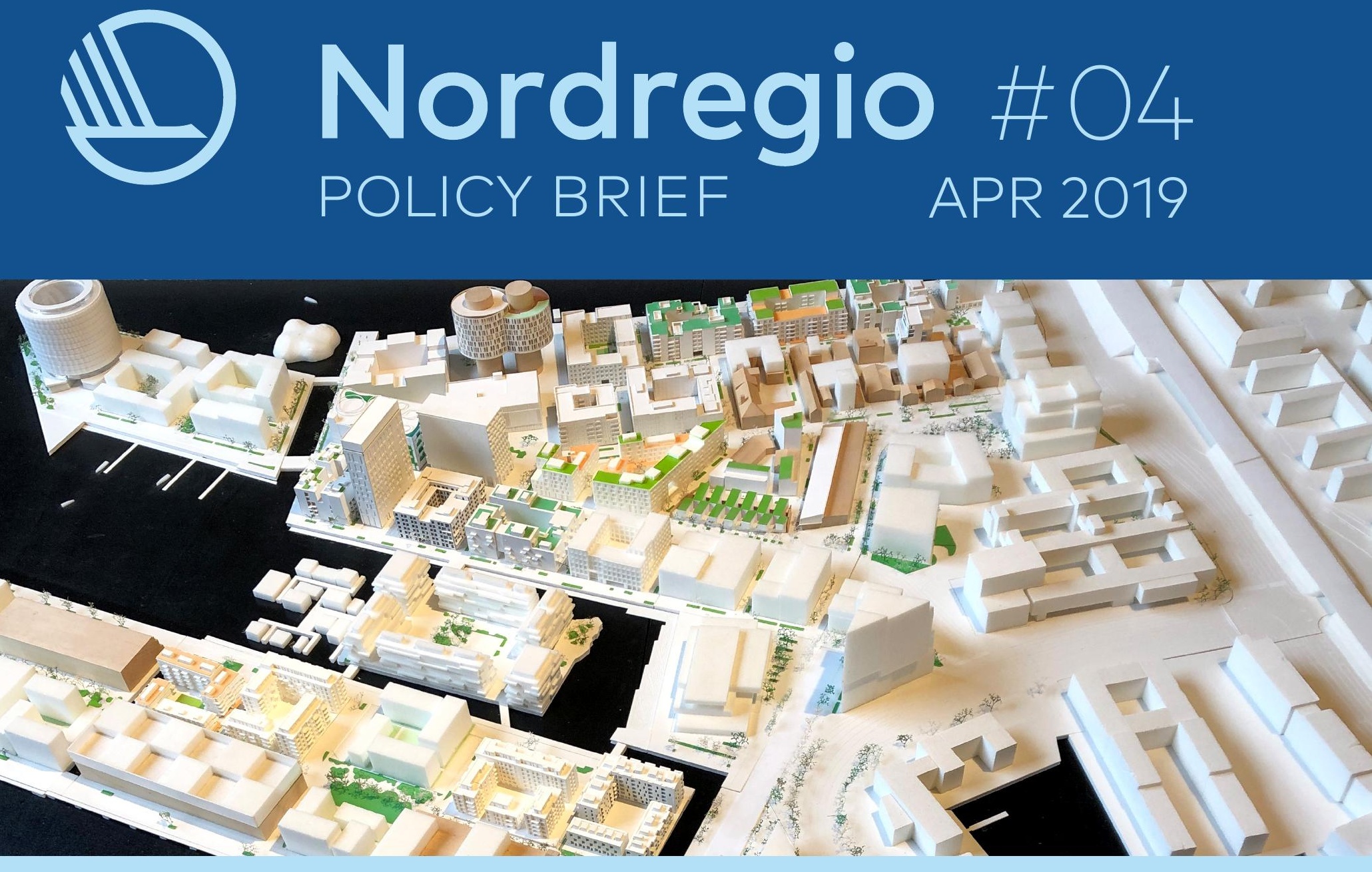

\title{
Forskning och praktik i samverkan om medborgardeltagande $i$ stadsplanering
}

På Nordregio arbetar forskarna i nära samarbete med tjänstepersoner på lokal, regional eller nationell nivå. I det FORMAS-finansierade forskningsprojektet Medborgardeltagandets effekter där Nordregio ingår tillsammans med KTH och Göteborgs universitet, deltar representanter från 12 svenska kommuner i en referensgrupp. Här berättar vi om hur projektet präglas av det kontinuerliga samtalet mellan forskning och praktik, och gör ett nedslag i ett fördjupat samtal om praktikers lärdomar kring medborgardeltagande.

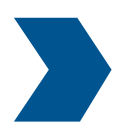

Forskningsprojektet som startade 2016 genomför bland annat en kartläggning av dialogaktiviteter i planeringsprocesser i tolv svenska kommuner mellan år 2000-2015. Kartläggningen är betydelsefull eftersom det inte sedan tidigare finns någon sammanställning av planprocesser som (utöver det obligatoriska samrådet) har innehållit dialogaktiviteter. Den är dessutom en utmaning, eftersom det inte finns någon exakt definition av vad en planeringsdialog är, eller några enhetliga former för hur dialogaktiviteter ska dokumenteras. Av bland annat dessa orsaker är 


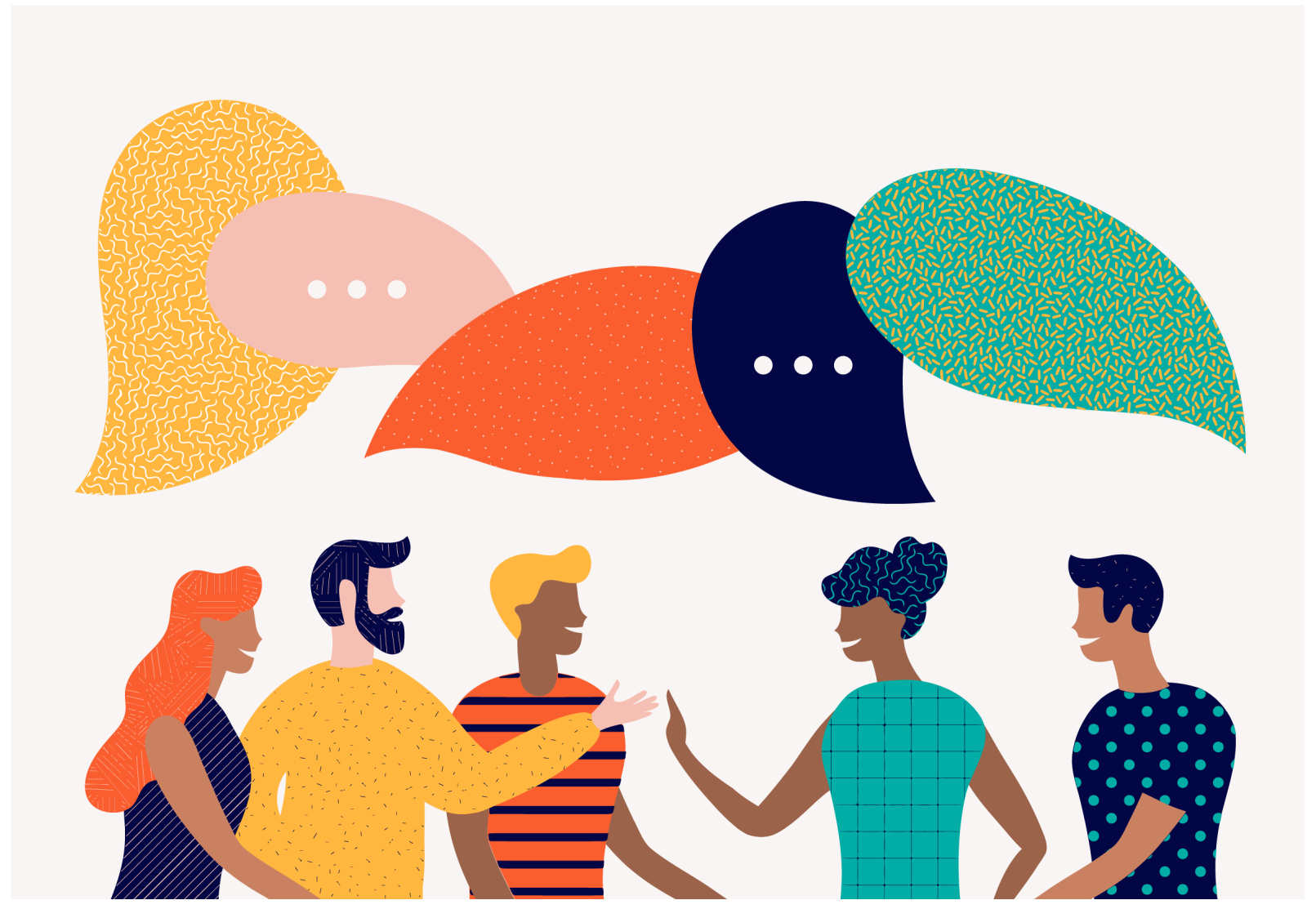

det återkommande samtalet mellan forskarna och referensgruppen med kommunala tjänstepersoner av stor vikt.

I projektet har forskarna och referensgruppen träffats fyra gånger sedan projektets start. Dessförinnan var en del av kommunerna med i ansökningsarbetet. De deltog både i projektutveckling och i planeringen av det empiriska arbetet. Träffarna och samtalen har gett input till projektet gällande bland annat hur svårigheter med materialinsamling kan hanteras i de olika kommunerna. Under projektets gång har det varit möjligt för kommunerna att dela med sig av sina respektive erfarenheter av att arbeta med medborgardeltagande samt att kommentera hur väl projektet har täckt in de dialogaktiviteter som de har genomfört. Arbetssättet påminner om hur projekt ofta är organiserade på Nordregio; kontinuerlig samverkan mellan forskning och praktik är central, liksom det gemensamma lärandet. I det här projektet har referensgruppen med kommunala tjänstepersoner tillsammans betydande erfarenhet av att arbeta med medborgardialog i planering.

Vid varje träff har erfarenheter utbytts om vad de ser som lyckade respektive mindre lyckade inslag eller förutsättningar för sitt dialogarbete. Medan forskarnas förhållningssätt i projektet huvudsakligen är analytiskt, kan tjänstepersonerna ha ett mer normativt perspektiv.

Tjänstepersonernas erfarenheter kan dessutom vara till gagn för andra praktiker och beslutsfattare. I oktober 2018 deltog representanter från fyra av de kommuner som är med i referensgruppen i en workshop hos Nordregio där syftet var att låta dem själva formulera sina erfarenheter av medborgardeltagande i planeringsarbetet.

\section{VARFÖR DISKUTERA HUR MEDBORGAR- DELTAGANDET KAN BLI MER MENINGS- FULLT?}

Workshopen och samtalet om hur medborgardeltagandet kan bli mer meningsfullt utgick från att det finns möjlighet att utveckla det. Samtalet tog avstamp i att det finns utmaningar i det praktiska utövandet, såsom vilka som ska bjudas in att delta och varför, eller vilka frågor som ska tas upp - eller inte tas upp. Och kanske framförallt - vad är medborgardeltagandets uppgift i planeringsprocessen i Sverige idag?

Planeringen som sådan är betydelsefull för framtiden. Enligt portalparagrafen i Plan- och bygglagen (2010) syftar bestämmelserna om planläggning till att "med hänsyn till den enskilda människans frihet, främja en samhällsutveckling med jämlika och goda sociala levnadsförhållanden och en god och långsiktigt hållbar livsmiljö för människorna i dagens samhälle och för kommande generationer". Man skulle alltså kunna fråga hur medborgardeltagande i planeringen kan bidra till detta. 'Meningsfull' betyder "som ger (djupare) mening" (Svenska Akademin 2018), och i det här fallet formulerade vi en fråga om "hur medborgardeltagandet kan bli mer meningsfullt för stadsplaneringen, medborgarna och 
demokratin". Frågan innehåller alltså ett antagande om att medborgardeltagandet ska ge mening till stadsplaneringsprocessen, som i sin tur ska skapa det samhälle som omskrivs i portalparagrafen i PBL. Frågan utgår också från att medborgardeltagandet ska ge mening till de som deltar, i det här fallet omnämnda som medborgare. Slutligen kan ett syfte vara att medborgardeltagandet ska gynna (fördjupa, stärka) den demokratiska beslutsprocessen. I det följande presenteras några teman som kom upp under workshopen med tjänstepersonerna. Texten kan läsas som erfarna praktikers reflektioner kring hur medborgardeltagande i planeringsprocesser kan utvecklas.

\section{DET BEHÖVER FINNAS EN PERSPEKTIVBREDD I DELTAGANDET}

Med perspektivbredd menade tjänstepersonerna att flera olika perspektiv eller sätt att se på en fråga finns med då frågan diskuteras. Det skiljer sig alltså från att olika grupper ska vara representerade. I samtalet framhölls att perspektivbredden gynnas om tjänstepersoner som arbetar med deltagande och dialog har bra verktyg för att göra målgruppsanalys, det vill säga ta reda på vilka det är som berörs av en fråga. Dessutom anses gruppen tjänstepersoner som arbetar med planering i offentlig sektor vara homogen idag, och en större spridning i tjänstepersonernas kontaktnät skulle därför också vara bra för perspektivbredden, menade man.

Genom att bjuda in till tillfällen för dialog och deltagande på ett målgruppsanpassat vis kan deltagandeprocessen tillgängliggöras för fler. Det är välkänt att valet av tid och plats för dialog påverkar vem som kan delta, men det bör understrykas, menade workshopdeltagarna. Ett alternativ till att bjuda in kan vara att söka upp specifika grupper, och att vara aktivt närvarande på den plats som frågorna berör, allt för att fånga in en bredd av perspektiv på de frågor som kommunen vill ha medborgarnas uppfattningar och kunskaper om.

Tjänstepersonerna betonade också att olika perspektiv, behov och kunskaper inte bara behöver finnas representerade eller komma till uttryck, utan att de ska kunna påverka utfallet av planeringen, det vill säga själva stadsmiljön. I så fall bör deltagandeprocessen utformas med detta som mål och kopplas till den formella planprocessen. Det aktualiserar återigen den viktiga, och svåra, diskussionen om vilka som ska ges inflytande. Det ansågs också viktigt att kommunen återkommande vänder sig till deltagarna under planeringsprocessens gång.

\section{INTRESSEKONFLIKTER BEHÖVER LYFTAS I PLANERINGSPROCESSER}

Både de som är boende på en plats, andra invånare, och aktörer från privat och offentlig sektor har intressen i stadsrummets utveckling. De som leder dialog- och deltagandeprocesser behöver ha kompetens och insikt om vikten av att synliggöra dessa. Under workshopen betonades betydelsen av att motstridigheter tas upp och diskuteras i planprocessens olika skeden.

Att lyfta intressekonflikter och visa vilka prioriteringar som görs är ett ansvar som i hög grad ligger på kommunen och den enskilda tjänstepersonen. Planeraren har verktyg såsom sitt tjänsteutlåtande, förstudie, barnkonsekvensanalys och social konsekvensanalys tillhanda, men det kan krävas mod för att använda dem för att lyfta motstående intressen och motivera och dokumentera prioriteringar. Tjänstepersonerna funderade på om det är själva planprocessens organisering som gör att intressekonflikter och resonemang om prioriteringar blir osynliga. I det slutliga plandokumentet syns inte avvägningarna, utan fokus är på den föreslagna planen som den bästa lösningen.

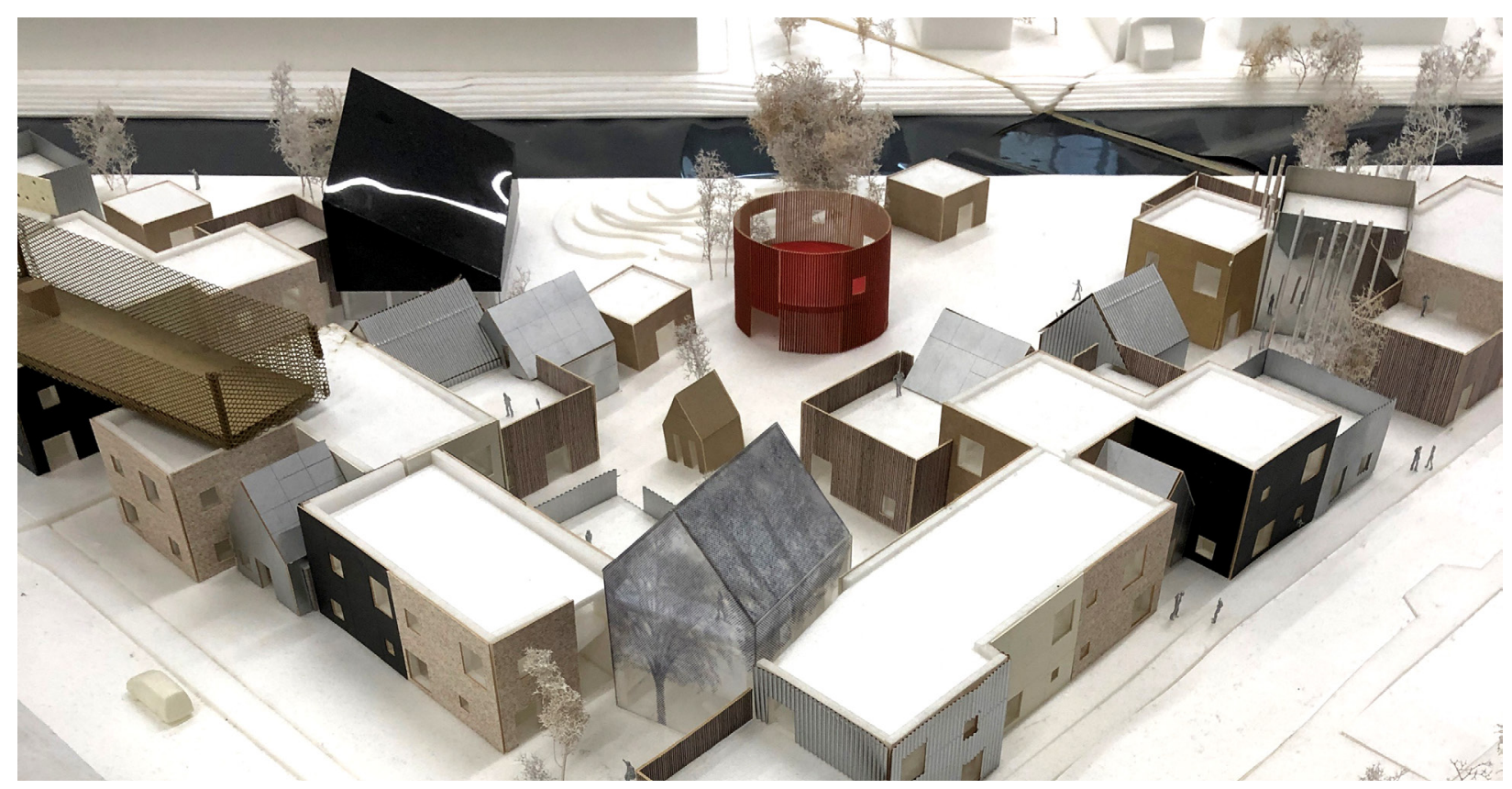


Ett exempel på hur intressekonflikter kan synliggöras i en medborgardialogprocess, är genom att deltagarna ombeds att prioritera mellan sina egna och andras intressen. Det kan gynna förståelse hos både deltagarna och planerarna kring de olika perspektiv som finns på en specifik planfråga.

\section{EN KONTINUERLIG DIALOG PÅ PLATS}

En gemensam plats såsom ett torg eller en park kan fungera som något som förenar människor. På en plats, i den lokala kontexten, kan möten ske som kanske inte sker annars. Oavsett samhällsåskådning, livsstil eller religion så kan boende engagera sig i sitt lokala torgs nya utformning eller i planer för nya bostäder i kvarteret.

Platsens betydelse belyses också genom vikten av närvaro. Kan planerare och tjänstepersoner finnas på plats, på ett medborgarkontor eller liknande, så finns förutsättningar för en kontinuerlig dialog med invånarna. Då ökar också möjligheten att den lokala kunskapen inkluderas i sådant som sociala konsekvensanalyser och barnkonsekvensanalyser menar tjänstepersonerna. En förutsättning för lokal närvaro är att kommunen har de ekonomiska, personella och organisatoriska resurser som behövs.

\section{ATT DELTAGANDET GÖR SKILLNAD OCH ÄR SYNLIGT FÖR INVÅNARNA INOM ÖVERSKÅDLIG TID}

I deltagandeprocesser framkommer ofta mindre förslag som kan genomföras innan planer vunnit laga kraft. Om kommunerna genomför sådana förslag så synliggörs deltagandets betydelse för invånarna tidigt. Även detta bygger dock på att det finns ekonomiska och organisatoriska resurser som gör det möjligt att snabbt realisera de synliga åtgärder som föreslagits. Detta betyder inte att sådant som är mer komplicerat eller tidskrävande ska förbises.

Avslutningsvis, i den här skriften har våra workshopdeltagares erfarenheter stått i fokus. Lärdomarna och råden riktas till personer som arbetar med medborgardeltagande på praktisk och strategisk nivå, samt till beslutsfattare som kan se till att det finns resurser för att organisera processer som gynnar ett meningsfullt deltagande - för demokratin, stadsplaneringen och medborgarna.

\section{OM DENNA POLICY BRIEF}

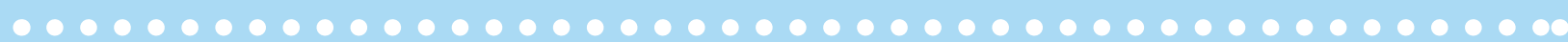

Fyra tjänstepersoner från Göteborgs stad, Tjörns kommun, Upplands Väsby kommun och Helsingborgs stad deltog vid workshopen.

Forskningsprojektet Medborgardeltagandets effekter

Projektet Medborgardeltagandets effekter: en kartläggning och utveckling av den kommunikativa planeringens omfattning, former och resultat undersöker inbjudet medborgardeltagande i stadsplaneringsprocesser i tolv svenska kommuner mellan år 2000 och 2015. Deltagare i projektet är Förvaltningshögskolan Göteborgs universitet, Kungliga Tekniska Högskolan (KTH), Nordregio samt kommunerna Stockholm, Nacka, Botkyrka, Upplands Väsby, Göteborg, Alingsås, Tjörn, Lerum, Malmö, Helsingborg, Lund och Landskrona. Associerade partners är: Trafikverket, Mistra Urban Futures, Boverket och SKL. Projektet finansieras av FORMAS, Mistra Urban Futures och Trafikverket. Projektet avslutas under 2020.
Kontakt:

Moa Tunström

Senior Research Fellow

moa.tunstrom@nordregio.org

Sandra Oliveira e Costa

Research Fellow

sandra.oliveiracosta@nordregio.org

\section{Bilder:}

Framsida och sidan 3: Johanna Feuk, Nordregio Sidan 2: Shutterstock

ISSN 2001-3876

URL: doi.org/10.30689/PB2019:4.2001-3876

www.nordregio.org 